\title{
MAIMONIDES EDITORIAL
}

Three contributions celebrate the occasion of the eight-hundredth anniversary of the death of one of our greatest sages, Moses Maimonides (1135-1204).

Maimonides was a master in every branch of Jewish scholarship. He was the great genius who synthesised the vast world of Talmudic law. He threw light on the Mishnah by one of the most lucid commentaries ever to have been written and he wrote numerous responsa advising Jewish community leaders on intricate problems of interpretation and application of rabbinical law. As a practising physician his advice on prophylaxis and medical treatment was highly valued, while he also had a keen interest in human psychology and in the natural sciences in general, including astronomy.

Maimonides' philosophical views are more difficult to access, partly because of the style and method employed by him in his Guide of the Perplexed. Joshua Levy considers in his contribution Maimonides' purpose for applying a certain tactical method and also considers his 'ideal reader' and the issue of 'perplexity' in a few short and well-focused paragraphs - an ideal introduction into Maimonides' main philosophical opus. A more detailed essay into the various possible approaches to Maimonides' Guide is presented by Donald McCallum who unravels the more important strands of recent interpretation given by contemporary Maimonidean scholars. We can enjoy this piece as a summary of their opinions, or else it can be read as a valuable introduction to the present discussion on how to approach Maimonides' Guide hermeneutically.

Using Aristotelian thought as a tool to question and to confirm revealed religion in the name of sufficiency of reason, Maimonides followed the Islamic philosophical tradition whose significance for Jewish thinkers cannot be overemphasised. The religious proximity of Judaism and Islam allowed Jewish philosophers to work within this tradition of Islamic philosophy itself, in which, for example, one of the most common topics of discussion could deal with the Deity and divine attributes. A flavour of Maimonides' treatment of the latter is given in a further short contribution by Joshua Levy reflecting discussions in class during the introductory course to Jewish philosophy for our first year students.

Maimonides' Guide subsequently became the basis of every philosophical interpretation of Judaism, while exercising also a marked influence on Christian scholasticism and modern rationalism.

But we should not forget that Maimonides also has a rightful place within the history of Islamic philosophy, for his ideas have been studied by Islamic thinkers to this day. We are honoured to be reminded of just how much 
Maimonides' ideas have been appreciated within Islamic culture by a comprehensive contribution of his general impact on Arab-Islamic education by His Royal Highness Prince El Hassan bin Talal of Jordan. His essay clarifies Maimonides' position against other Muslim streams of thought at the time, thereby addressing Maimonides' own view on Divine Providence and the interconnected problems of evil - a theme which is also taken up by Joshua Levy with great succinctness and clarity.

Prince El Hassan bin Talal draws a beautiful mosaic of Maimonides' multifarious personality, reminding us of three interrelated aspects of education which our own Centre for Jewish Education may wish to consider. Most touching, perhaps, is his appreciation of Maimonides' 'humanitarian work free from any religious or denominational discrimination'. All three contributions bring together Maimonides' outstanding achievements in both theory and practice which, as he himself would maintain, only as a fusion constitute the proper worship of God.

Esther Seidel 